\title{
Level of aspiration and motor performance in prospective scientists and in underachieving secondary school boys'
}

Anthony Davids and Jack Sidman 2 BROWN UNIVERSITY

\begin{abstract}
Abstraet
In comparison with a group of boys with outstanding academic records in the sciences, a group of bright underachieving boys performed less effectively on their first approach to a motor-manipulation task and evidenced a lower initial level of aspiration (LA). When their second motor performance attained or surpassed their LA, the underachievers then set a goal that was similar to the level aspired to by the boys who were accustomed to high academic attainment.
\end{abstract}

\section{Introduetion}

Two groups of secondary school students participated in experimental educational programs at Brown University. One group (high achievers) was composed of academically successful students enrolled in a summer science program. These students were rated as highly intelligent by school administrators, were in the top $10 \%$ of their class, with honor grades in science courses, and had demonstrated outstanding potential for careers in science. The other group (underachievers) was composed of bright students (mean $\mathrm{IQ}=126$ ) who were failing in regular school work and were enrolled in a summer academic potential project. The students in both groups were administered a battery of clinical and experimental assessment procedures designed to reveal motivational and performance differences.

\section{Method}

This paper reports findings from a level of aspiration (LA) experiment conducted with 10 high achievers (mean age $=16.4$ years) and 20 underachievers (mean age $=15.6$ years). Using the Minnesota Rate of Manipulation Form Board, Ss were run individually in accord with the following procedure. $S$ was instructed to turn over as many blocks as he could during a 30-sec. trial. Following this first trial, E recorded and announced the number of blocks turned, and asked S, "How many do you think you can turn over in another $30-\mathrm{sec}$. trial ?" Following this second trial, E again recorded and announced the number of blocks turned, and asked $S$ to state the number he believed he could turn over if he were given a third trial. This procedure provides two measures of motor performance, two measures of LA, and several discrepancy scores between measures of LA and performance.

\section{Results and Discussion}

On the first trial, the high achievers turned a mean of 49 blocks which is noticeably higher $(p=.07)$ than the mean of 43 in the group of underachievers. Follow- ing this performance, Ss in the high achiever group stated a mean LA of 51.5 which is also noticeably higher $(p=.06)$ than the mean LA of 46.6 in the group of underachievers. However, on the second trial there was hardly any difference between the two groups, with the high achievers turning a mean of 50.8 blocks and the underachievers turning a mean of 50 blocks. Following this second trial, the high achievers stated a mean LA of 52.7 which was very similar to the mean LA of 52.4 in the group of underachievers. Thus, in comparison with the high achievers, the underachievers performed less effectively on their first approach to this motor task and evidenced a lower initial LA. When their second performance attained or surpassed their LA, they then set a goal that was similar to the level aspired to by a group of boys who were accustomed to high achievement in academic situations.

In examining differences in discrepancy scores, it was found that more of the underachievers tended to set higher LAs in comparison with their pastperformances than did the high achievers. None of these differences between the two groups was significant, but they do reveal a consistent trend suggesting that for some of these underachievers, the tendency to set their LA higher than their performance might, in other situations, lead to a succession of failing experiences. That is, if one follows a performance which is not outstanding with setting of an LA that is much higher, he is likely to meet with failure. In order to function effectively, one must realistically appraise his past performance and accurately estimate his future performance, thereby setting goals that he is likely to attain.

In interviewing underachievers, one frequently encounters a sub-variety who say how determined they were to get all As and Bs at the start of a new term, following a term in which they had attained mainly failing grades. For a while they may try to work toward their high aspirations, but when the results start coming in they become disappointed and, in response to the failure experiences, tend to give up until another term comes along. It is noble to set high goals, but probably wiser, and psychologically more healthy, to set goals that are in keeping with one's abilities and are likely to be met with success. Would not a series of small successes that can be attained realistically be more beneficial to one's personal adjustment than an imagined great success that is destined to end in failure? 
Table 2

Percentage of Choice of $\mathrm{Al}$ and $\mathrm{B} 2$

Strategies by Individual column

and Row Players Over All 200 Trials

Game No.

Percent Choice of

Al

B2

1

60.0

51.0

2

61.5

49.5

3

82.0

61.0

4

76.5

73.5

5

75.5

62.5

6

66.5

66.0

7

64.5

44.0

8

68.0

54.0

9

70.0

52.0

that there is some slight tendency, over the 200 trials, for the Ss' choices to approach the minimax prescription.

When the curves describing the individual Ss' choices are examined the behavior of many Ss shows a tendency to come closer to the prescription of the minimax model as trials progress. Analyses of the choices of individual Ss indicate that some of them, over the final 75-100 trials, did make their choices in percentages apparently consistent with the proportions prescribed by the minimax model. Analyses of data not presented here indicate that seven of the row players and three of the column players made their choices in conformity with the proportions prescribed by the minimax model. Some of these players chose A1 and B2 in the prescribed proportions over the whole 200 trials; others started by making their choices contrary to the prescription of the model, but as the trials progressed came closer and closer to the prescription of the model. ${ }^{3}$
Table 2 shows the percentages of choice of A1 and B2 strategies by individual column and row players. The percentages of choice of $\mathrm{A} 1$ vary around the $75 \%$ prescription: 3 are greater than $75 \%$; 6 are less than $75 \%$. All the percentages of choice of B2 are less than $75 \%$. The analyses discussed above, of the choices of individual $\mathrm{Ss}$, might lead to the conclusion that on the final 75 to 100 choices 10 of the $18 \mathrm{Ss}$ conformed to the prescription of the minimax model. However, a reasonable interpretation of what the minimax model dictates, requires that $\mathrm{Ss}$ be able to state that they were choosing A1 and B2 with the probability 0.75; and that they made their choices using some approximation of randomization. Analyses of the questionnaires the Ss completed indicated that they believed that they should not make their choices conform to any predictable pattern. However, virtually all of the Ss did not have an overall strategy of playing their alternatives with some fixed probability. Ss tried to predict what their opponent would do on each play by looking for patterns in his play, and by other means. It is this fact, that Ss did not state that they should make their choices in some fixed proportion, that Ss did not adopt a randomized strategy, that leads to a rejection of the minimax model as descriptive of the present data. However, this rejection of the model should be considered together with the fact that 10 of $18 \mathrm{Ss}$, on the final 75-100 trials were making their choices in proportions consistent with the dictates of the minimax model.

\section{Reference}

LIEBERMAN, B. Experimental studies of conflict in some twoperson and three-person games. In J. H. Criswell, H. Solomon, and P. Suppes (Eds.), Mathematical Methods In Small Group Processes. Stanford, California: Stanford U. Press, 1962. Pp. 203-220.

Notes

1. This work was done as part of an undergraduate research course taken by the first author at the State University of New York at Stony Brook, and supervised by the second author. Reprints can be obtained from Lieberman.

2. The statistical questions involved in determining whether the Ss choices conformed to the minimax model are many and complex. Discussion of these questions can be found in a document entitled Supplementary Discussion of the Behavior of Responsive Individuals Playing 'a Two-Person, Zero-Sum Game Requiring the Use of Mixed Strategies. To obtain a copy of this material write to B. Lieberman, 1009 CL, University of Pittsburgh, Pittsburgh, Pennsylvania, 15213.

3 . The choices of each individual $S$ (by trial block) are included in the document cited in footnote 2. 